\title{
EVIDENCE FOR THE BENEFITS OF EXERCISE FROM EPIDEMIOLOGICAL STUDIES
}

\author{
J. N. MORRIS, CBE, DSc, MD, FRCP \\ Professor of Community Health, London School of Hygiene and Tropical Medicine
}

\begin{abstract}
At the end of World War Two, the N.I.H. in America set up the Framingham study to examine the factors contributing to the epidemic of coronary heart disease, and the Medical Research Council in this country established the Social Medicine Research Unit with one of its main objectives to study coronary heart disease.
\end{abstract}

\section{OCCUPATIONAL STUDIES}

We set about doing studies of various population groups defined by occupation. At that time, virtually nothing was known of the epidemiology or aetiology of coronary heart disease.

One of the first groups was London Transport bus drivers and conductors. We found that there was a slightly lower incidence of coronary events in the conductors, but when we looked at the most serious form of the disease, sudden death occurring without warning in men under 50 years of age, the conductors had only one third the incidence of drivers.

Now this goes back to $1949 / 1950$ and in those days the first explanation we thought of was what is now called "stress". This was the teaching of Sir Thomas Lewis in the 1930s to account for the then much less common disease. We abandoned this idea after doing studies on other occupational groups. For example we found differences between clerks and postmen in a study in the Civil Service. Stress would not account for the higher incidence in the clerks who overall had a slightly higher experience of the disease, but when rapidly fatal infarction in men under $\mathbf{5 0}$ years of age was compared, the postmen had $30 \%$ of the experience of the clerks.

This suggested to us an alternative hypothesis, that it was not stress but the amount of exercise that differed between the jobs and might account for their different experience of coronary disease. Manifestly the London Transport conductor on a double-decker bus has a more active occupation than the driver who has a sedentary job. Equally postmen who were found by work study to spend $70 \%$ of their time walking, cycling and carrying the mail were more active than the clerks.

We continued with these studies. Similar studies were done in other countries, some with similar results, some different.

We eventually abandoned these studies of occupa- tional differences in coronary experience, and relating this to levels of exertion, for two important reasons.

The first was the problem of self selection. How much of the differences that we were seeing were the result of different sorts of people taking up different occupations, and how much to the work experience of the job itself? This apparently simple problem, is one of the most important in epidemiology, and most difficult to eliminate.

The second reason why we moved away from occupational differences was that, if we are to make use of exercise in preventing coronary heart disease, we must concentrate on leisure-time exertion. With the increasing mechanisation of jobs, fewer and fewer involve significant physical exertion, and the study of these occupations was becoming less and less relevant to the main problem of coronary disease.

\section{LEISURE ACTIVITY}

We therefore set about looking at physical activity in leisure time to see whether there was any relationship between that and the experience of coronary heart disease. We spent several years looking at the methodology, as we were not at all happy with the methods that we hạd.

We eventually identified a population, in fact, 17,000 middle-aged civil servants, of the executive grade from six government departments. This is an intermediate grade between clerical and administrative. They were all sedentary office workers.

What we did was to take a sample of their behaviour. They filled in a detailed five minute by five minute questionnaire on how they had spent an unannounced Friday and Saturday.

By arrangement with the trade unions, details of any serious subsequent illnesses were also made available to us, along with the results of all these personal logs of how they had spent a Friday and Saturday.

Initially we concentrated on total physical activity from these personal logs, in relationship to subsequent coronary disease, and found none.

However, we did find a clear relationship, and we had 
not expected this, between vigorous physical exercise and subsequent coronary events. We found that where we matched men having their first coronary attack against matched controls, similar age, department etc. the men suffering their first coronary were much less likely to have taken any vigorous exercise on the two days studied than their matched controls.

One of the difficulties was to grade the severity of physical activity, taken during leisure. These men were great gardeners, but the amount of effort put into gardening in physical terms can be very variable. These men were also great "Do it Yourselfers", painting and decorating.

The only type of activity appearing to have much importance was physical activity involving a caloric expenditure of greater than 7.5 kilocalories per minute, equivalent to heavy industrial work. This was found to include digging, swimming, tennis, hill climbing, running, squash, vigorous walking at over four miles per hour, cycling, tree felling; only the heaviest "Do it Yourself" qualified. Swimming I put first of the sports. It is my favourite exercise, and, in light of what we have been hearing today, worth remarking that it is virtually impossible to hurt yourself swimming.

We have now taken a sample of these 17,000 men and are doing a total mortality study on 3,600 men between 40 and 65 years of age. Over the years many of these men have died. Of the total sample 777 reported taking vigorous exercise, between $25 \%$ and $20 \%$ of the total.

The differences in mortality per year from coronary heart disease, 1.0 for the exercise group against 4.3 for the others. For other causes of death there was no significant difference. However coronary heart disease contributes such a large fraction of total mortality in this population, as in many others studied, that the difference in coronary mortality has a major effect on the total mortality.

Other aspects of this study. On 500 of these men we have made a detailed medical and biochemical study. Of these, the ones reporting vigorous physical exercise showed far fewer ECG changes suggestive of ischaemia than their less vigorous controls, $4.8 \%$ against $10.4 \%$ when standardised for age. The next finding was to me even more interesting a striking difference in the frequency of ectopic beats between these two groups $2.2 \%$ against $7.1 \%$. These included supraventricular and ventricular ectopic beats.

A point raised by Tunstall Pedoe is especially important; vigorous exercise seems to exert a protective effect. There was no difference for example between the casual blood pressure readings of these two groups that we studied, but when we related the ECG abnormalities to the casual blood pressure reading, we not surprisingly found that there was a much higher frequency of ECG abnormalities at the higher pressures, even though they were not very high. This is exactly what one would expect, but at each level of raised pressure the men reporting vigorous exercise had many fewer ECG abnormalities than their matched controls, not engaging in vigorous exercise. There are a wide variety of similar bits of evidence suggesting that exercise exerts a protective effect. Of course exercise alters a wide range of physiological functions, but it is interesting to observe how many of them are altered in a beneficial way. This is of course a very important field for continuing study.

\section{PAFFENBARGER'S STUDIES}

Now let me just refer briefly to some work being done in the U.S.A. by Paffenbarger, a leading man in the field, who has continued in the study of occupational differences. He has studied San Francisco longshoremen, with sophisticated techniques and made a mortality study of coronary heart disease, in various grades of these dockers, graded on the basis of the physical exertion involved in their jobs. He has also followed them through to note any changes in their occupations (to answer the question as to whether less fit men take a series of jobs requiring less and less physical exertion). They were graded into three grades. The heavy workers had coronary mortality rates substantially below those of the other groups, suggesting a threshold effect, similar to what we found with our leisure time activities of civil servants.

He has approached the problem of selection, between the groups. He has said, "Here are different groups of men with different occupations, are they different in important respects with respect to coronary heart disease? Do they smoke differently, have different blood pressures, different cholesterols?"

Strikingly enough there was no significant differences between the groups in these respects, so the differences in coronary mortality could not be accounted for by selection with respect to these factors.

Another interesting study has recently been conducted by Paffenbarger. He got in touch with all the 16,000 Harvard graduates over the course of many years, and obtained a medical history, and a history of their student existence including their sporting activities. He also asked about any continuing, athletic activity.

He showed that if an athlete at University continued his sport, this seemed to confer a protective effect against the subsequent development of coronary disease, BUT he was not protected against heart disease in middle age any more than men of the same age who took the same amount of exercise and who were not 
athletes as students. If a student athlete did not continue to take regular exercise, his student activity seemed to exert no subsequent protective effect with respect to coronary heart disease.

This I think is one of the most interesting studies with respect to the arguments about self selection.
It is very important that the B.A.S.M. takes a lead in studying the different forms of exercise and their benefits. Vigorous exercise is very different from just a general increase in physical activity, and a clear message is needed as to which forms of exercise are most beneficial. Funds are available for this type of research and much more research is needed.

\section{REFERENCES}

Morris, J. N., Heady, J. A., Raffle, P. A. B. et al. 1953. Coronary heart disease and physical activity of work, Lancet, 2 1053-1057 and 1111.

Morris, J. N., Kagan, A. et al. 1966. Incidence and prediction of ischaemic heart disease in London busmen. Lancet, 2 553-559.

Morris, J. N., Chave, S. P. W., Adam, C., et al. 1973. Vigorous exercise in leisure time and incidence of coronary heart disease. Lancet, 1 333-339.

Morris, J. N. 1975. Uses of Epidemiology. 3rd edn. Edinburgh and London.

Paffenbarger, R. S. and Hale, W. E. 1975. Work activity and coronary heart mortality. New Eng.Jnl.Med. 292 545-550.

Paffenbarger, R. S. (unpublished) Observations on Harvard graduates. The relationship between continuing physical activity and coronary disease. 